\title{
POLYARTHRITIS AS THE INITIAL MANIFESTATION OF LYMPHOMA IN CHILDREN - CASE REPORT
}

Olívia Regina Lins Leal Teles ${ }^{1, \star}$, Max Luan de Carvalho Aragão1, Yure Guimarães Azevedo¹, Tatiana Barbosa Castelo Branco ${ }^{1}$, José Caetano Macieira ${ }^{1}$, Lina Oliveira de Carvalhoํㅜㄹ Regina Adalva de Lucena Couto Océa ${ }^{1}$, Mônica Valéria Siqueira Santana de Vechi ${ }^{1}$

1.Universidade Federal de Sergipe, São Cristóvão (SE), Brazil.

*Corresponding author: oliviaa.teles@gmail.com

\section{BACKGROUND}

Joint manifestations are common in neoplastic processes in pediatric patients and are usually displayed as asymmetric polyarticular, oligoarticular or monoarticular arthritis of rapid onset. In children, the differential diagnosis may be juvenile idiopathic arthritis, spondyloarthritis, and rheumatic fever, among others. The objective was to describe the case of a child with polyarthritis initially treated as rheumatic fever which eventually was diagnosed with lymphoma after workup.

\section{CASE REPORT}

Male patient, 10 years old, with pain in the left shoulder and persistent fever $\left(39^{\circ} \mathrm{C}\right)$, even with the use of symptomatic drugs. He developed migratory polyarthritis of large joints that later presented additive pattern with maintenance of intermittent fever, intense pain in the right paravertebral muscles of dorsal spine and weight loss of $8 \mathrm{~kg}$ (approximately $20 \%$ of previous weight). He was admitted to a tertiary hospital where treatment with crystalline penicillin and analgesia with opioids was initiated, with partial improvement, due to suspected rheumatic fever. He was later transferred to a specialized pediatric hospital proceeding with further workup. Laboratory tests showed elevated acute-phase proteins, anemia, ANA, rheumatoid factor, antistreptolysin O, and oropharyngeal culture were negative, tuberculin test $22 \mathrm{~mm}$. Computed tomography of the thoracic spine showed diffuse reduction of the vertebral body height of T9, with increased bone density. Bone marrow biopsy of iliac crest showed small cell neoplasm. After these results, he was transferred to an oncology center where he started chemotherapy.

\section{CONCLUSION}

This is a case of polyarthritis of large joints secondary to hematologic neoplasm in pediatrics.

\section{KEYWORDS}

Lymphoma, Polyarthritis, Pediatrics. 